\title{
AUMENTO DA PRODUÇÃO DE ETANOL A PARTIR DE MELAÇO DE CANA-DE-AÇÚCAR PELA ADIÇÃO DE BENZOATO
}

\author{
L. E. GUTIERREZ ${ }^{1}$ \\ A.V.K.O. ANNICHINO ${ }^{1}$ \\ L. LUCATTI ${ }^{1}$ \\ S.B. LEITE DA SILVA ${ }^{1}$
}

RESUMO: O efeito da adição de benzoato de sódio sobre a fermentação alcoólica de meio de melaço de cana-de-açúcar com $15 \%$ de açúcares redutores totais foi estudado utilizando a levedura industrial Saccharomyces cerevisiae M-300-A. Foram adicionados 7,5 miligramas de benzoato de sódio para 0,8 gramas de levedura seca durante $0,2,4$ e 6 ciclos fermentativos. Com a adição de benzoato ocorreu aumento na produção de etanol, redução do crescimento da levedura e dos teores de glicerol e dos álcoois n-propilico, isobutílico e isoamílico. O inibidor não provocou redução da viabilidade celular e após a retirada do inibidor a levedura voltou a apresentar crescimento. Este fato sugere a possibilidade do uso do benzoato em destilarias de álcool combustível.

Termos para Indexação: etanol, fermentação alcoólica, benzoato, melaço.

1 Departamento de Química da Escola superior de Agricultura "Luiz de Queiroz" da Universidade de São Paulo, 13400 - Piracicaba - SP e CEBTEC/FEALQ. 


\section{ENHANCEMENT IN ETHANOL PRODUCTION FROM CANE MOLASSES BY BENZOATE ADDITION}

AB8TRACT: The effect of the addition of sodium benzoate on alcoholic fermentation of molasses medium with 158 total reducing sugars was studied by using industrial yeast Saccharomyces cerevisiae M-300-A. Sodium benzoate was added at the rate of $7.5 \mathrm{miligram}$ to 0,8 grams of dry yeast during $0,2,4$ e 6 fermentative cycles. The addition of sodium benzoate resulted in an increase in ethanol production and a reduction of yeast growth and glycerol and n-propylic, isobutylic and isoamylic alcoholic contents. The inhibitor did not reduce cell viability; soon after its removal the yeast returned to grow. This fact suggests the possibility of using the benzoate in distilleries. Index Terms: ethanol, alcoholic fermentation, benzoate, molasses.

\section{INTRODUÇĀo}

No Brasil, o etanol é uma fonte de energia alternativa que tem sido usada como combustível para automóveis desde 1979 com grande sucesso. Para melhorar o rendimento da fermentação etanólica e por conseguinte aumentar a produção de etanol, seleção e isolamento de leveduras que toleram altas temperaturas e alta concentração de açúcares tem sido feita (SANTOS, 1988; ERNANDES et alii, 1990).

Também foram estudadas as caracteristicas da composição das leveduras. GIUDICI et alli (1983) relataram que uma correlação linear positiva entre o teor de acido oleico e a produtividade de etanol em 22 linhagens de Saccharomyces cerevisiae, enquanto que WATSON (1982) relatou que células enriquecidas com ácidos graxos insaturados produziram altas concentraçōes de etanol. NAGAR-LEGMANN \& MARGALITH 
(1987) relataram que a levedura altamente fermentativa não apresentou ácidos graxos poliinsaturados como linoleico e linolênico. E também OHTA \& HAYASHIDA (1983) verificaram que a adição de ergosterol e ácido oleico provocou aumento na produção de etanol durante a fermentação de "sake" além de reduzir o tempo da fermentação.

Outras possibilidades para se aumentar a produção de etanol foram relatadas como a adição de óleos vegetais (SAIGAL \& VISHWANATHAN, 1983), ferrocianeto (ODERINDE et alii, 1986), leite desnatado (PATIL et alii, 1986) e óleo de soja (ALTERTHUM \& CRUZ, 1987). Sendo que a adição de sais de magnésio (DOMBEK \& INGRAM, 1986) e de cálcio (NABAIS et alii, 1988) melhoraram a toleráncia das leveduras ao etanol durante a fermentação alcoólica e que a adição de ergosterol a mosto de uva aumentou a fermentação do açúcar em condições anaeróbicas (LARUE et alii, 1980).

Uma outra possibilidade de aumentar a produção de etanol é reduzir a formação de massa celular pelo uso de inibidores metabólicos (AMIM et alii, 1984; GUTIERREZ, 1989), mas infelizmente ocorre perda de viabilidade celular, o que impossibilita o uso no sistema atual de reciclagem de fermento utilizado no Brasil para a produção de etanol.

No presente trabalho um aumento significativo na produção de etanol a partir do melaço é apresentado pela adição de benzoato de sódio sem ocorrer perda de viabilidade celular.

\section{MATERIAL E METODOS}

Levedura: foi utilizada uma linhagem industrial de Saccharomyces cerevisiae M-300-A, fornecida pelo Departamento de Genética da Escola Superior de Agricultura "Luiz de Queiroz" da Universidade de São Paulo. A levedura foi multi- 
plicada anaerobicamente em meio de melaço com $3 \%$ de açúcares redutores totais, pH 5.0, suplementado com $150 \mathrm{ppm}$ de nitrogênio amoniacal na forma de sulfato de amônio e $100 \mathrm{ppm}$ de fósforo na forma de fosfato dibásico de potássio, e esterilizado a $121^{\circ} \mathrm{C}$ durante 20 minutos. A multiplicação foi realizada a $25 \pm 1{ }^{\circ} \mathrm{C}$ durante 36 horas com agitação ocasional. A levedura foi centrifugada e lavada com água gelada. Foram colocados em cada tubo de fermentação 0,8 gramas de levedura com base na matéria seca.

Meio de melaço para fermentação: melaço de cana-de-açúcar da Usina $M B$ do Estado de São Paulo, safra 89, foi diluído até 15\% de açúcares redutores totais, $\mathrm{pH}$ acertado a $4.0 \mathrm{com}$ solução de ácido sulfúrico e esterilizado a $121^{\circ} \mathrm{C}$ durante 20 minutos. O meio foi suplementado com 1,0 grama de sulfato de amônio e 0,55 gramas de fosfato dibásico de potássio por litro.

Ensaio de fermentação: foram realizados dois ensaios. No primeiro, $50 \mathrm{ml}$ de meio de melaço com $15 \%$ de açúcares redutores totais contendo $150 \mathrm{ppm}$ de benzoato de sódio foram adicionados ao fermento de uma só vez. No segundo, $20 \mathrm{ml}$ de uma solução de $375 \mathrm{ppm}$ de benzoato de sódio foram adicionados ao fermento e em seguida foram adicionados $10 \mathrm{ml}$ de meio de melaço a $21 \%$ de açúcares redutores totais por hora até 50 ml. Nos dois ensaios a fermentação foi realizada a $32+1{ }^{\circ} \mathrm{C}$ em frascos cilindricos de 150 $\mathrm{ml}$, em duplicata, e na presença do inibidor benzoato durante $0,2,4$ e 6 primeiros ciclos de fermentação. Os frascos foram pesados de hora em hora para verificar a produção de gás carbônico e o final da fermentação. o tempo de fermentação foi de cerca de 8 horas nos dois ensaios. Após o final da fermentação, foram coletadas amostras para determinar a viabilidade celular e o meio fermentado foi centrifu- 
gado sendo o sobrenadante utilizado para as análises de etanol, glicerol, álcoois superiores e açúcares redutores residuais e a levedura foi reutilizada durante oito ciclos fermentativos.

\section{ANÁLISES}

Viabilidade celular: foi determinada de acordo com PIERCE (1970) utilizando azul de metileno como indicador.

Etanol: foi determinado por densimetria segundo AMORIM et alii (1979).

Glicerol: foi analisados colorimetrimente segundo descrito em ZAGo et alii (1989).

Álcoois superiores: foram identificados e quantificados por cromatografia em fase gasosa (CG17) como descrito em GUTIERREZ (1988).

Açúcares redutores: foram determinados pelo método de Somogyi-Nelson adaptado por AMORIM et ali $\mathrm{i}$ (1982).

Análise estatística: foi adotado o delineamento inteiramente casualizado com oito repetiçōes segundo GOMES (1970).

\section{RESULTADOS E DISCUSSĀO}

Na Tabela 1 é apresentado o efeito da adição do inibidor benzoato junto com a adição do meio de melaço de uma unica vez. Com a adição do benzoato durante os dois primeiros ciclos (tratamento B) já ocorreu aumento não significativo ( $p>0,05)$ na produção de etanol e redução significativa $(p<0,05)$ no teor de glicerol e no peso úmido do fermento sem ocorrer alteração significativa na viabilidade 
Tabela 1 - Efeito do benzoato de sódio com adição única do meio de melaço com $15 \%$ de ART sobre a fermentação alcoólica (médias de 8 ciclos fermentativos).

\begin{tabular}{|c|c|c|c|c|c|c|}
\hline \multirow{2}{*}{ COMPONENTES } & & \multicolumn{5}{|c|}{ TRATAMENTOS* } \\
\hline & A & B & $c$ & $\mathrm{D}$ & C.V. & dms 5\% \\
\hline $\begin{array}{l}\text { Etanol } \\
\text { (\& vol.) }\end{array}$ & 7,80 & 7,95 & 8,07 & 8,12 & 2,56 & 0,205 \\
\hline $\begin{array}{l}\text { Glicerol } \\
(\mathrm{g} / 100 \mathrm{ml})\end{array}$ & 0,76 & 0,70 & 0,66 & 0,63 & 6,12 & 0,042 \\
\hline $\begin{array}{l}\text { Peso úmi- } \\
\text { do }(\mathrm{g})\end{array}$ & 7,79 & 7,05 & 6,75 & 6,57 & 5,35 & 0,379 \\
\hline $\begin{array}{l}\text { Viabili- } \\
\text { dade (z) }\end{array}$ & 95,85 & 95,45 & 95,91 & 94,71 & 3,93 & 5,113 \\
\hline $\begin{array}{l}\text { N-Propi- } \\
\text { lico }(\mathrm{mg} / \mathrm{l}\end{array}$ & 50,6 & 36,8 & 26,7 & 19,3 & 27,59 & 9,269 \\
\hline $\begin{array}{l}\text { Isobuti- } \\
1 \mathrm{ico}(\mathrm{mg} / \mathrm{l})\end{array}$ & $\begin{array}{l}54,3 \\
)\end{array}$ & 48,7 & 47,3 & 39,3 & 22,16 & 10,569 \\
\hline $\begin{array}{l}\text { Isoam } 1- \\
1 \text { ico }(\mathrm{mg} / \mathrm{l})\end{array}$ & $\begin{array}{l}79,5 \\
1\end{array}$ & 71,2 & 61,2 & 52,7 & 13,80 & 9,182 \\
\hline
\end{tabular}

* Tratamentos: A (sem inibidor)

B (inibidor nos dois primeiros ciclos)

C (inibidor nos quatro primeiros)

D (inibidor nos seis primeiros) 
celular. Com a adição do benzoato nos quatro ciclos iniciais (tratamento c) e seis ciclos (tratamento D) ocorreram aumentos significativos $(p<0,05)$ na produção de etanol e reduções significativas $(\mathrm{p}<0,05)$ nos teores de glicerol, álcoois n-propilico, isobutilico e isoamilico e no peso úmido do fermento. Em todos os tratamentos com adição de benzoato não ocorreu redução significativa $(p<0,05)$ na viabilidade celular. Comparando-se os tratamentos $C$ e D não se observa aumento significativo na produção de etanol e redução significativa nos teores de glicerol e do peso úmido.

Na Tabela 2 são apresentados os teores de etanol, glicerol, álcoois n-propilico, isobutilico e isoamilico, o peso úmido do fermento e a viabilidade celular de fermentaçós com adição inicial do inibidor benzoato e adição parcelada do meio com $10 \mathrm{ml}$ por hora até 50 $\mathrm{ml}$. Com apenas duas adições do inibidor (tratamento B) ocorreu aumento da produção de etanol embora não significativa $(p>0,05)$, porém ocorreu redução significativa na formação de glicerol, do peso úmido do fermento e do álcool n-propilico sem alterar significativamente a viabilidade celular. Com a adição de inibidor nos quatro primeiros ciclos (tratamento c) ocorreram aumentos significativos $(p<0,05)$ na produção de etanol e redução no glicerol, peso úmido e nos álcoois n-propilico, isobutilico e isoamilico, não se observando efeitos sobre a viabilidade celular.

Não se observa na Tabela 2 efeito benéfico significativo com o auamento do número de ciclos de benzoato de quatro (tratamento $c$ ) para seis (tratamento D).

Comparando-se os dados das Tabelas 1 e 2 observa-se uma nitida vantagem da adição parcelada do meio sobre a adiçāo única tanto no tratamento testemunha como com inibidor. Ocorreu maior produção de etanol e do crescimento do fermento com menor formação de glicerol. 
Tabela 2 - Efeito do benzoato de sódio com adição parcelada de meio de melaço sobre a fermentação alcoólica. (Média de 8 ciclos fermentativos).

\begin{tabular}{|c|c|c|c|c|c|c|}
\hline \multirow{2}{*}{ COMPONENTES } & \multicolumn{6}{|c|}{ TRATAMENTOS* } \\
\hline & A & B & $c$ & D & c.v. & dms 58 \\
\hline $\begin{array}{l}\text { Etanol } \\
\text { (\& vol.) }\end{array}$ & 8,13 & 8,27 & 8,36 & 8,38 & 2,83 & 0,219 \\
\hline $\begin{array}{l}\text { Glicerol } \\
(\mathrm{g} / 100 \mathrm{ml})\end{array}$ & 0,58 & 0,50 & 0,46 & 0,43 & 8,00 & 0,037 \\
\hline $\begin{array}{l}\text { Peso úmi- } \\
\text { do }(g)\end{array}$ & 9,80 & 8,14 & 7,82 & 7,68 & 10,96 & 0,857 \\
\hline $\begin{array}{l}\text { Viabili- } \\
\text { dade (z) }\end{array}$ & 93,15 & 96,66 & 96,82 & 96,52 & 3,75 & 3,618 \\
\hline $\begin{array}{l}\text { N-Propi- } \\
\text { lico }(m g / 1)\end{array}$ & 42,5 & 29,0 & 21,4 & 17,6 & 23,44 & 6,058 \\
\hline $\begin{array}{l}\text { Isobut } 1- \\
\text { lico }(\mathrm{mg} / 1)\end{array}$ & 41,7 & 37.7 & 35,0 & 28,8 & 14,39 & 4,818 \\
\hline $\begin{array}{l}\text { Isoami- } \\
\text { lico }(\mathrm{mg} / \mathrm{l})\end{array}$ & 80,4 & 71,5 & 65,2 & 52,5 & 13,88 & 8,749 \\
\hline
\end{tabular}

* Tratamentos: A (sem inibidor)

B (inibidor nos dois primeiros ciclos)

C (inibidor nos quatro primeiros)

D (inibidor nos seis primeiros) 
o efeito do benzoato sobre o crescimento da levedura em oito ciclos fermentativos pode ser visto na Figura 1 . Com a adição do inibidor nos dois primeiros ciclos ocorreu redução do peso úmido do fermento e o efeito prolonga-se por mais dois ciclos e a partir do 59 ciclo iniciou-se uma recuperação do fermento atingindo um máximo no 89 ciclo. Fenômeno semelhante se repetiu com os tratamentos com adição nos 4 e 6 primeiros ciclos, demonstrando que 0 inibidor se acumula na levedura ou apresenta um efeito prolongado sobre o metabolismo da levedura.

A formação de glicerol é afetada pela adição do benzoato durante os 8 ciclos fermentativos como pode ser visto na Figura 3 . Ocorre redução de glicerol com a adição do inibidor, porém, retirando-se o inibidor, o teor de glicerol torna a aumentar.

Comparando-se as Figuras 1,2 e 3 pode ser observado que, com a diminuição do glicerol e do peso úmido ocorre maior produção de etanol. Em relação ao etanol (Figura 2), notase que mesmo após a retirada do inibidor a produção de etanol continua maior do que a testemunha.

Nas Figuras 4 e 5 pode-se observar 0 efeito do benzoato sobre a produção dos álcoois n-propilico e isoamílico, respectivamente. Ocorre redução desses álcoois enquanto a presença do inibidor. Retirando-se o inibidor a produção aumenta e atinge valores próximos da testemunha.

o benzoato é um preservativo de largo uso sendo mais efetivo contra leveduras do que bactérias, sendo a ação germicida devido à parte não dissociada da molécula, o que explica o maior poder em meio ácido (DESROSIER, 1970). No caso de ser utilizado nas fermentações alcoólicas é uma vantagem pois após o tratamento ácido do fermento, o pH do início da fermentação é normalmente baixo. 


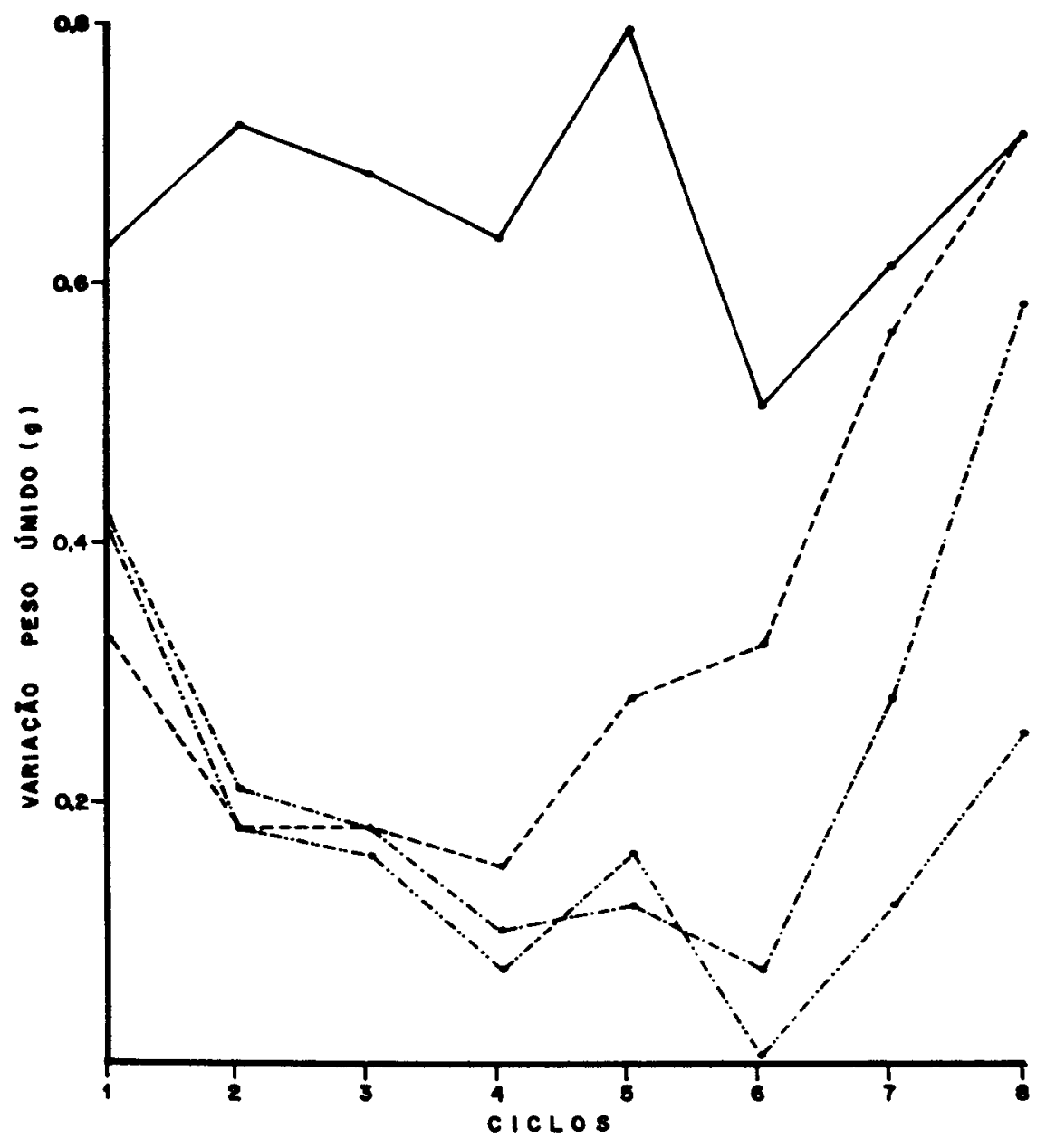

FIQURA 1 : EFEITO DO DEMZOATO DE SÓDIO SOARE O PESO ÚMIDO DO FERMENTO EM - CICLOS FERMENTATIYOS (aDICXO PARCELADA DO MEIO)

- SEM INIOIDOR: - - - IMIDIDON MOS \& PRIMEIROS CICLOS:

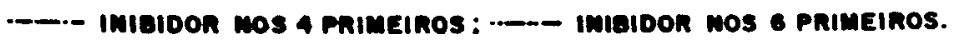




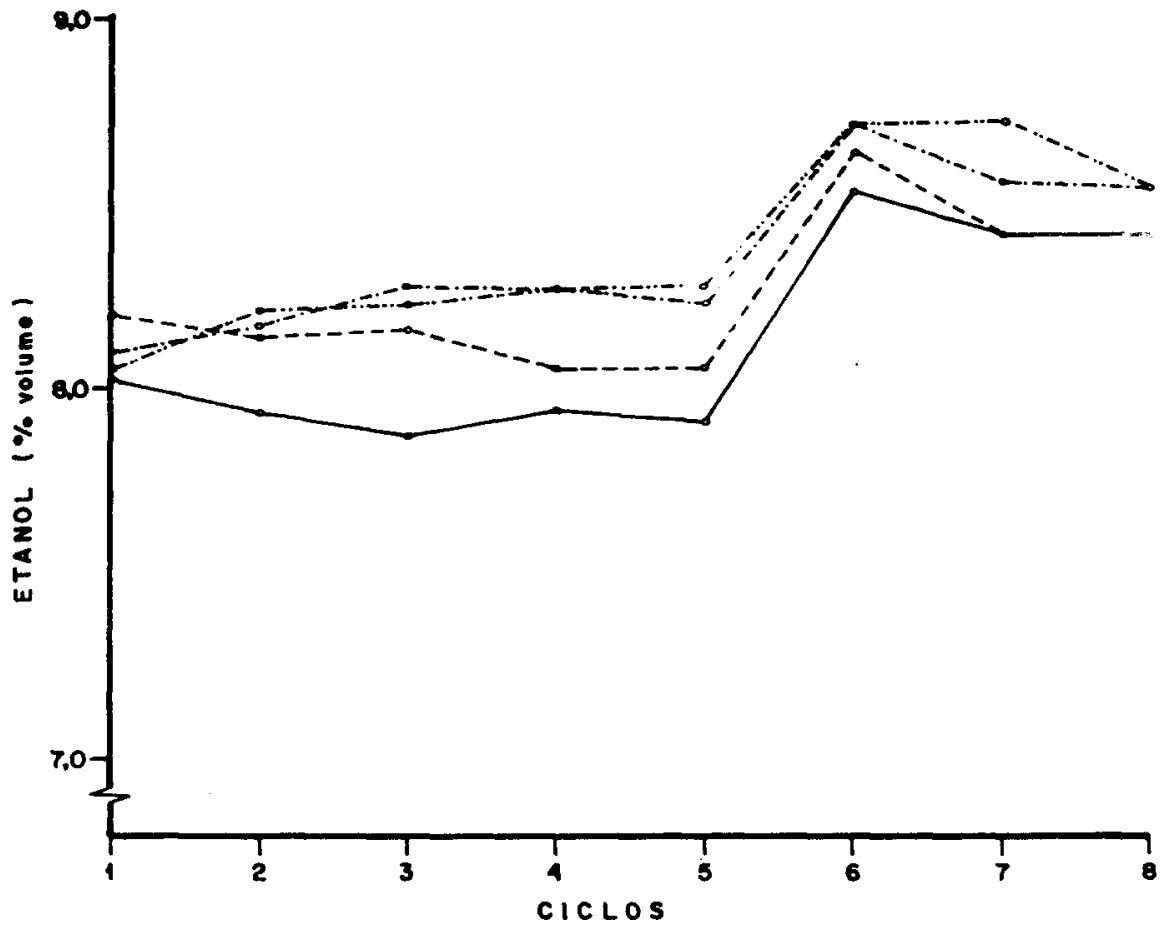

FIGURA 2 : EFEITO do genzoATO SOARE A PRODUCÃo de ETANOL EM 9 CICLOS FERMENTATIVOS ( COM ADICÃo PARCELADA) - SEM INIBIDOR: - - INIBIDOR NOS 2 PRIMEIROS CICLOS: -...- INIBIDOR MOS 4 PRIMEIROS : - -..... INIBIDOR NOS 6 PRIMEIROS. 


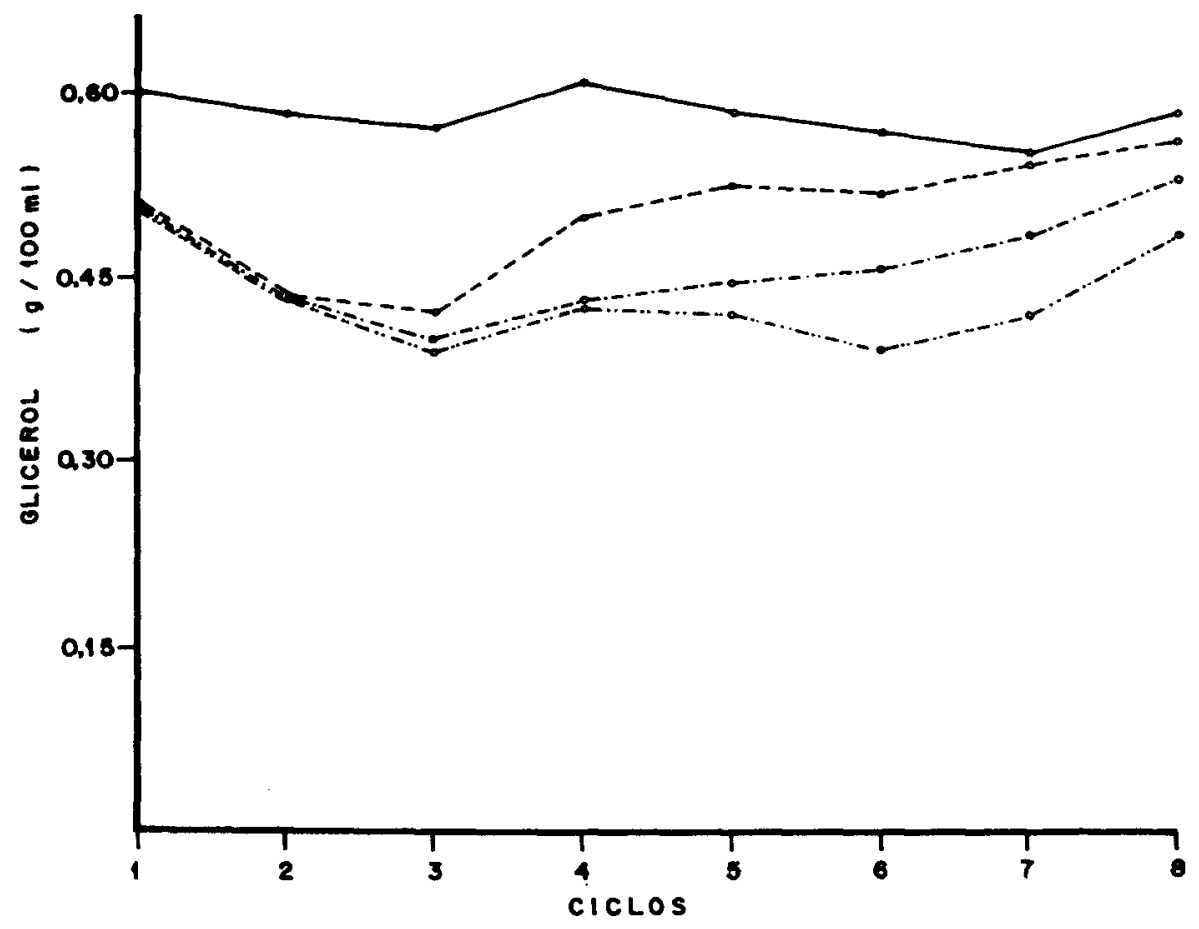

FIQURA 3 : EFEITO DO BENZOATO DE SÓDIO SOBRE A FORMACÃO DE GLICEROL EM - ciclos fermentativos (adicão parcelada do melo)

- SEM INIEIDOR: - - - IMIBIDOR MOS 2 PAIMEIROS CICLOS:

-.--- INIBIDOR NOS 4 PRIMEIROS:-..-... IMIEIDOR MOS B PRIMEIROS. 


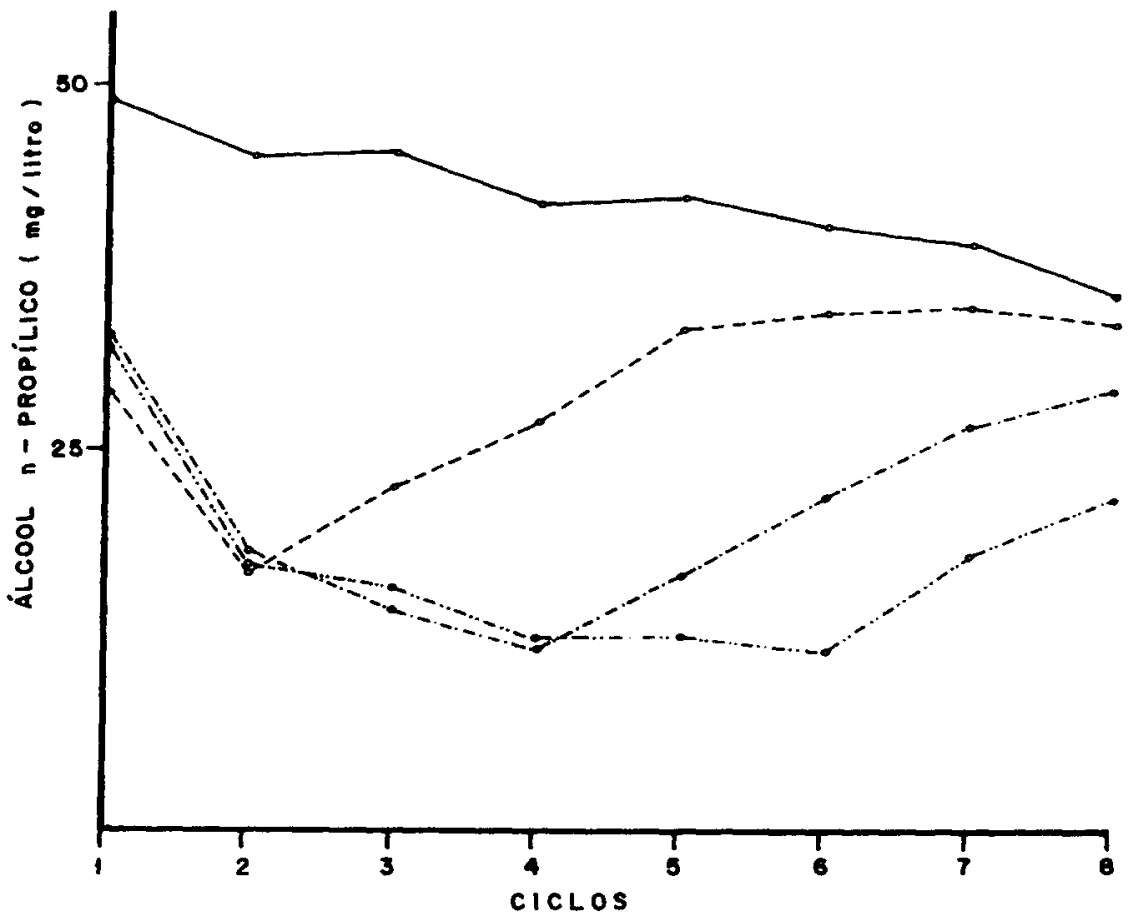

figuaA 4: efeito do genzoato de sódio sobre a producAo de ÁlCOOL n-PROPÍlLICO EM C CICLOS FERMENTATIVOS ( ADICÃO PARCELADA DO MEIOI — SEM INIBIOOR:--- INIBIDOR NOS 2 PRIMEIROS CICLOS: -.-. IMIBIDOR NOS 4 PRIMEIROS : - -..- INIBIDOR NOS 6 PRIMEIROS. 


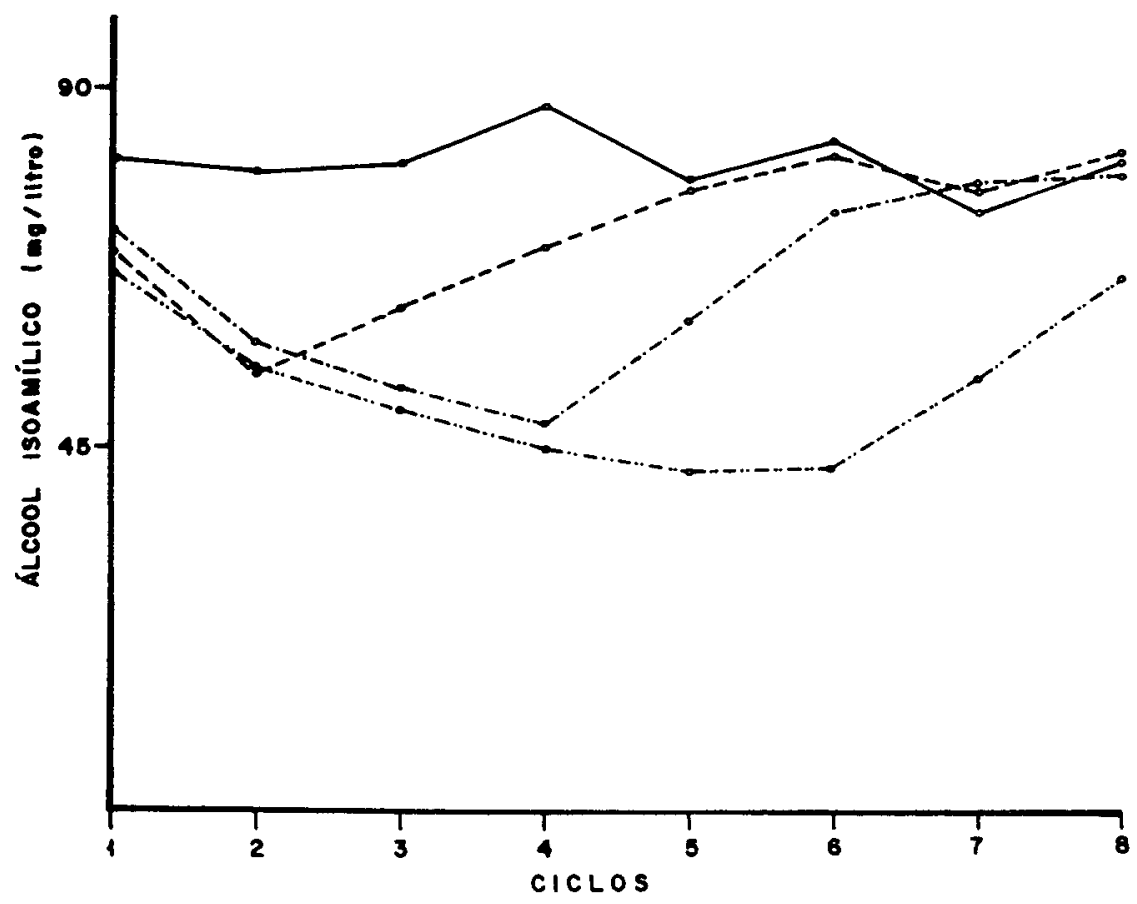

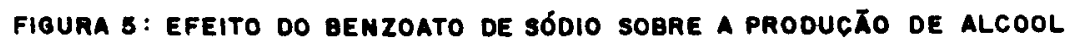
ISOAMÍlICO EM C CICLOS FERMENTATIVOS (ADICX̃o PARCELADA DO MEIO) - SEM INIBIDOR:---- INIBIDOR NOS 2 PRIMEIROS CICLOS: ....- INIBIDOR NOS 4 PRIMEIROS: ........ INIBIDOR NOS 6 PRIMEIROS. 
NORDSTROM (1966 e 1968) relatou que a formação de glicerol é dependente do crescimento da levedura, demonstrando que 0,69 gramas de glicerol são formados por grama de matéria seca produzida pela levedura. Nas Tabelas 1 e 2 pode-se observar uma queda do teor de glicerol que acompanha a redução do peso úmido do fermento evidenciando a relação entre glicerol e crescimento da levedura. A levedura reduzindo - crescimento e a produção de glicerol passa a produzir maior quantidade de etanol confirmancir. observações de GUTIERREZ (1989).

A sintese de glicerol também está relacionada com a formação de ácido succínico; com a redução da formação desse ácido ocorre redução na produção de glicerol e aumento na produção de etanol (OURA, 1977). Os precursores para a síntese do ácido succínico pela via oxidativa são o ácido oxaloacético e acetilcoenzima-A. A formação do ácido oxaloacético é realizada pela piruvato carboxilase, enzima que é ativada por acetil-coenzima-A (PALACIAN et alii, 1966; CAZZULO \& STOPANI, 1968). Dessa forma a redução do nível de acetil-coenzima-A deve ser acompanhada por redução do ácido succínico e do glicerol. GRIFFITH et alii (1989) relataram que benzoato compete com acetato pela formação de éster de coenzima-A e assim reduzindo $o$ nivel de acetil-coenzima-A formada e portanto a atividade da piruvato carboxilase. Uma outra enzima inibida por benzoato é a tirosinase do cogumelo Agaricus bisporus (MENON et alii, 1990). No presente trabalho foi apresentado nas Tabelas 1 e 2 e na Figura 5, uma redução na produção de álcool isoamílico com a adição de benzoato. Este fato vem confirmar a menor formação de acetilcoenzima-A com o uso do inibidor pois para a síntese de ácido alfacetoisocapróico (precursor da leucina e do álcool isoamilico) é necessário acetil-coenzima-A (LEHNINGER, 1970). Da mesma forma, ocorreu redução no álcool n-propilico 
(Figura 4), provavelmente devido à menor formação do ácido oxaloacético pela piruvato carboxilase e portanto, menor produção de ácido aspartico, que, ao lado da glicina, é um dos precursores da treonina e do álcool n-propilico.

A redução na produção de álcoois superiores pode ser uma outra vantagem com 0 uso do benzoato na fermentação alcoólica, pois possibiliota a obtenção de etanol de maior pureza, embora reduza a produção de óleo fusel.

outros inibidores como 2,4-dinitrofenol também reduzem ácido succínico (DURO \& SERRANO, 1981), a produção de matéria seca da levedura e o teor de glicerol durante a fermentação alcoólica (AMIN et alii, 1985; GUTIERREZ, 1989). Porém, nesses trabalhos também ocorreu diminuição da viabilidade celular das leveduras, provavelmente porque o 2,4-dinitrofenol afeta a sintese de ATP nas células das leveduras, o que não ocorre com o benzoato. Assim, embora a produção de etanol seja maior, o inibidor 2,4-dinitrofenol não pode ser usado num sistema de reciclo de fermento como é usado nas destilarias brasileiras.

\section{CONCLUSÃo}

A adição de benzoato durante a fermentação alcoólíca provocou maior formação de etanol, redução do crescimento da levedura $e$ menor produção de glicerol e de álcoois superiores sem afetar a viabilidade celular. 


\section{REFERÊNCIAS BIBLIOGRÁFICAS}

ALTERTHUM, F. \& CRUZ, M.R.M. Aumento do rendimento da fermentação alcoólica pela adição de óleo de soja. Revista de Microbiologia, São Paulo, 18 (1): 52-7, 1987.

AMIN, G.; P. STANDAERT \& H. VERACHTERT. Effects of metabolic inhibitors on the alcoholic fermentation by several yeasts in batch or in immobilized cell systems. Applied Microbiology, Berlin, 19: 91-9, 1984 .

AMORIM, H.V.; ZAGO, E.A.; GUTIERREZ, L.E. Método rápido para o controle da fermentação e destilação. Saccharum STAB, São Paulo, 4: 31-43, 1979.

AMORIM, H.V.; ZAGO, E.A.; OLIVEIRA, A.J. Novos métodos para o controle da fermentacão alcoólica. São Paulo, Socieda de Brasileira de Microbiologia, 1982. 58p.

CAZZULO, J.J. \& STOPPANI, A.O.M. The regulation of yeast pyruvate carboxylase by acetyl-coenzyme-A and L-aspartate. Archive of Biochemistry and Biophysics, New York, 127: 563-7, 1968 .

DESROSIER, N.W. The technology of food preservation. Westport, AVI, 1970. 493p.

DOMBEK, K.M. \& INGRAM, L.O. Magnesium limitation and its role in apparent toxicity of ethanol during yeast fermentation. Applied and Environmental Microbiology, Baltimore, 토:975-81, 1986. 
DURO, A.F. \& SERRANO, R. Inhibition of succinate production during yeast fermentation by deenergization of the plasma membrane. Current Microbiology, New York, 6 : 111-3, 1981 .

ERNANDES, J.R.; MATULIONIS, M. ; CRUZ, S.H.; BERTOLINI, M.C.; LALUCE, C. Isolation of new ethanol-tolerant yeasts for fuel ethanol production from sucrose. Biotechnology Letters, Kew, 12 (6): 463-8, 1990 .

GIUDICI, P. ; GUERZONI, M.E. ; CONTE, L. Relationship of cellular fatty acid compositor to the ethanol productivity in Saccharomyces cerevisiae. Vini D'Italia, 25: (145):147-53, 1983 .

GOMES, F.P. Curso de Estatistica Experimental São Paulo, Nobel, 1970.485p.

GRIFFITH， A. D. ; CYR, D.M.; EGAN, S.G.; TREMBLAY, C.C. Inhibition of pyruvate carboxylase by sequestration of coenzyme A with sodium benzoate. Archives of Biochemistry and Biophysics. San Diego, 269 (1): 201-7, 1989.

GUTIERREZ, L.E. Efeito dos ácidos fórmico e propiônico sobre a produção de álcoois superiores durante a fermentação alcoólica Anais da Escola Superior de Agricultura "Luiz de Queiroz", Piracicaba, 45 (2):369379,1988 .

GUTIERREZ, L.E. Estudo comparativo da fermentação alcoólica por linhagens de Saccharomyces cerevisiae e saccharomyces uvarum. Piracicaba, 1989. 160p. (LivreDocência - Escola Superior de Agricultura "Luiz de Queiroz"/USP). 
LARUE, F ; LAFON-LAFOURCADE, S ; GAYON, P.R. Relationship between the sterol content of yeast cells and their fermentation activity in grape must. Applied and Environmental Microbiology, Baltimore, $\underline{39}$ (4): 808-11, 1980 .

LEHNINGER, A.L. Biochemistry. New York, Worth, 1970. $833 \mathrm{p}$.

MENON, S.; FLECK, R.W.; YONG, G.; STROTHKAMP, K.G. Benzoic acid inhibition of the alpha, beta and gama isozymes of Agaricus bisporus tyrosinase. Archives of Biochemistry and Biophysics, New York, 280 (1): 27-32. 1990 .

NABAIS, R.C.; CORREIA, I.S.; VIEGAS, C.A.; NOVAIS, J.M. Influence of calcium ion on ethanol tolerance of Saccharomyces bayanus and alcoholic fermentation by yeast. Applied and Environmental Microbiology, Baltimore, 54 (10): 2439-46, 1988 .

NAGAR-LEGMANN, R .; MARGALITH, P. A comparative study of the lipid composition of yeasts with different fermentative capacities. Applied Microblology and Biotechnology. Berlin, 26:49-54, 1987.

NORDSTROM, $K$. Yeast growth and glycerol formation. Acta Chemica Scandinavica, Copenhagen, 20 (4). 1016-25, 1966 .

NORDSTROM, K. Yeast growth and glycerol formation. II Carbon and redox balances. Journal of the Institute of Brewing, London, 74: 429-32. 1968. 
ODERINE, R.A.; NGOKA, L.C.; ADESOGAN, E.K. Comparative study of the effect of ferrocyanide and EDTA on the production of ethyl alcohol from molasses by Saccharomyces cerevisiae. Biotechnology and Bioengineering, New York, 28: 1462-5, 1986.

OHTA, K. \& HAYASHIDA, S. Role of tween 80 and monoolein in a lipid-sterol-protein complex which enhances ethanol tolerance os sake yeasts. Applied and Environmental Microbiology, Baltimore, $\underline{46}(4): 824-5,1983$.

OURA, E. Reaction products of yeast fermentations. Process Biochemistry, Rickmansworth, 12: 19-35, 1977.

PALACIAN, E.; TORRONTEGUI, G.; LOSADA, M. Inhibition of yeast pyruvate carboxylase by L-aspartate and oxaloacetate. Biochemical and Biophysical Research Communications, San Diego, 24 (5): 644-9, 1966.

PATIL, S.G.; GOKHALE, D.V.; PATIL, B.G. Enhancement in ethanol production from cane molaasses by skim milk supplementation. Enzyme and Microbial Tecnology, Guildford, $\underline{8}$ : 481-4, 1986.

PIERCE, J.S. Institute of Brewing: analysis committee measurement of yeast viability. Journal of the Institute of Brewing. London, 16 (5):442-3, 1970 .

SAIGAL, D. \& VISWANATHAN, L. Effect of oils and fatty acids on the tolerance of distiller's yeast to alcohol and temperature. International sugar Journal. Port Talbot, $85(1017): 266-9,1983$. 
SANTOS, M. N. G. Seleção de leveduras termotolerantes para a produção de etanol. Viçosa, 1988. (Dissertação - Universidade Federal de Viçosa).

WATSON, $K$. Unsaturated fatty acid but not ergosterol is essential for high ethanol production in Saccharomyces. Biotechnology Letters, Kew, 4 (6): 197-402, 1982.

ZAGO, E.A.; AMORIM, H.V.; BASSO, L.C.; GUTIERREZ. L.E. ; OLIVEIRA, A.J. Métodos analiticos para o controle da produção de etanol. Piracicaba, ESALQ, Centro de Biotecnologia Agrícola, 1989, $144 \mathrm{p}$. 